be heartily congratulated on his work, which is interesting and readable from start to finish; while the illustrations, reproduced from his own photographs, are in most cases exquisite, as our readers may see for themselves from the two examples furnished herewith. Although he appears to have little or nothing new to record, Mr. Ward is evidently a careful and accurate observer, with the faculty of recording his facts in language that " can be understanded of the people."

With the exception of one chapter on the hydra and a second on the "tongues" of molluses, Mr. Ward's work is restricted to insects and plants. In his opening chapter he details the fascinating life-history of the orange-tip butterfly, showing how its coloration harmonises with the plants it frequents, and how the beautiful green mottling on the hind wings is produced by the blending of dots of black and yellow. As an example of the author's skill in microscopic photography, we reproduce from this chapter his enlarged figure of the egg of the butterfly in question.

Another chapter we have read with special interest is the one on the gorse, in which the author points out how this plant retains evidence of its relationship to the clovers in the form of its seed-leaves; while ht also suggests that the broom may be regarded as in some degree representing a plant in course of evolution to the gorse type, but that its career to this goal has been checked by the fact of its having a bitter taste, which renders its leaves, unlike those of the gorse, uneatable by cattle, so that a protective panoply of spines is superfluous. As a specimen of the author's exquisite photographs of plants, we reproduce the one showing the broom in blossom. Of the other chapters dealing with plants, one is devoted to their hairs and scales, in the course of which the author expresses his belief that he has brought to notice a hitherto undescribed type (in the Auricula); a second chapter is accorded to the sensitive plant, a third to the flowers of woodland trees, a fourth to plant-battles, and a fifth to plants that catch flies.

Reverting to the zoological series, it may be mentioned that the devotion of two chapters to the biographies of a couple of nearly allied species of hawk-moth is perhaps an ill-judged arrangement, as giving too much importance to one group. Be this as it may, the chapter entitled "Living Files and Rasps," in which are described and figured the lingual ribbons of a number of species of gastropods, can scarcely fail to be generally interesting, although it would have been better had the author in every case particularised the genus and species to which his specimens pertain, instead of merely labelling them "snails." In the chapter on mosquitoes and gnats the author does his best to clear up the popular misconception with regard to these insects, and shows how the female, so far as mankind is ooncerned, is the source of all harm and evil.

While, as already stated, it is somewhat marred by errors and inelegances of style, the book as a whole may be pronounced decidedly interesting and attractive, and free from all cant and faddism.

R. L.

\section{GERMAN EDUCATIONAL EXHIBITS AT ST. LOUIS.}

THE German educational exhibit at St. Louis was, as is usual with German exhibits, remarkably complete, and to enhance its value a series of descriptive catalogues was issued. Among the science catalogues were three on scientific instruments, chemistry, and medicine respectively which have special interest for readers of NATURE. They are all on the same plan, and include a general introduction ex- planatory of the scope of the work, and a detailed account of the apparatus, \&c., exhibited. They served a twofold purpose, that of informing visitors to the exhibition as to what there was to see, and also that of bringing together an account of the best products of German workmanship in the respective subjects of the catalogue.

In the catalogue of scientific instruments the introductory description is very full and of real use; special reference is made to novel instruments. Dr. Lindeck, of the Reichsanstalt, who edited the catalogue of the German exhibit in Paris in 1900, is responsible for this, while Dr. Krüss had charge of the section.

The description of the instruments which follows is arranged alphabetically according to the names of the exhibitors. The system of classification with cross references is somewhat less complete than that adopted in the 1900 catalogue, but by aid of the introduction it is easily possible to find any given kind of apparatus. A glance through the catalogue is sufficient to show its utility, and it is to be hoped that the support given to the proposed optical convention and exhibition in May next will be sufficient to justify the committee in issuing a catalogue of English optical goods which will serve the same purpose.

The chemical section at the exhibition contained a reading-room and library, and in this an interesting collection of alchemistic work was shown. Besides these most of the important modern German works on chemistry were to be found on the shelves. Two very interesting exhibits were the alchemistic laboratory, containing partly original apparatus, partly copies of old examples from the museum in Nuremberg, and the Liebig laboratory, a faithful copy of the well-known laboratory at Giessen. The rest of the exhibition illustrated modern chemical apparatus, methods and preparations.

The object of the medical exhibit is said to have been "to show how the German universities deal with the subject of medical instruction," and this was attained by judiciously grouping the articles shown, and by carefully selecting the apparatus. Naturally, various methods are adopted in the different branches; thus, in the department of internal medicine a complete clinical lecture on the diagnosis and therapeutics of tuberculosis is included, the objects required for demonstrating it being exhibited.

Among the apparatus, the microscopes and projection apparatus of Karl Zeiss occupy a prominent place.

It is noteworthy that among the infectious diseases and disease germs tuberculosis comes first.

The catalogue contains a full list of the exhibits with some account of the principal among them, and it is clear that great pains have been taken to secure that the primary object of the exhibition should be carried out.

The three catalogues, in their completeness and orderly arrangement, are examples of the German plan of carrying the teaching and method of science into everyday life.

\section{NOTES.}

THE council of the Linnean Society has appointed a committee to consider the question of zoological nomenclature.

Prof. Lanckrkaux has been elected president for 1905 of the Societé internationale de la Tuberculose.

ThE Canadian Government has decided to place a Marconi wireless telegraph station on Sable Island. The station will come into operation by August I next.

M. PAUL LABBt has been appointed general secretary of the Paris Society of Commercial Geography in success on to the late $\mathrm{Ch}$. Gauthiot. 